[CONTRIBUTION FROM THE LNIVERSITY OH TORONTO.]

\title{
FRIEDEL AND CRAFTS' REACTION. THE CARBOMETHOXY- BENZOYL CHLORIDES WITH AROMATIC HYDROCARBONS AND ALUMINUM CHLORIDE.
}

\author{
By Maurice E. Smith.
}

Received May 18, 1921.

Roser ${ }^{1}$ obtained the amyl ester of benzoyl-formic acid from the acid chloride of mono-amyl oxalate, benzene and aluminum chloride. This preparation suggested the use of the acid chlorides of the mono-alkyl esters of the phthalic acids for the preparation of various keto acids.

The isophthalic acid and the terephthalic acid were prepared by the oxidation of commercial xylene, which had been fractionated with a $150 \mathrm{~cm}$. column, by Professor Kenrick in this laboratory. It was found that the fraction boiling at $138.2^{\circ}$ to $138.4^{\circ}$ gave the largest yield of terephthalic acid.

Oxidation of the Xylene.-Fifty g. of xylene, b. p. $138.2^{\circ}$ to $138.4^{\circ}$, 5 liters of water and $30 \mathrm{~g}$. of sodium hydroxide were heated to $90^{\circ}$ in a 10-liter can which had a tight-fitting cover containing openings for condenser, mechanical stirrer and thermometer. All the openings were made steam tight. To the mixture was added $300 \mathrm{~g}$. of potassium permanganate in 4 equal portions at half-hour intervals. After 19 hours' heating at $85^{\circ}$ to $95^{\circ}$ the solution was decolorized with methyl alcohol, cooled, filtered and the filtrate acidified. The precipitate dried at $110^{\circ}$ weighed $60 \mathrm{~g}$.

Separation of the Acids.-This product was found to be practically free from phthalic acid which is soluble $0.58 \mathrm{~g}$. in $100 \mathrm{~g}$. of water at $20^{\circ}$. The isophthalic acid and terephthalic acid were separated by means of their barium salts. The solubility of barium terephthalate and barium isophthalate, determined by evaporating a saturated solution and drying the residue at $200^{\circ}$ for 8 hours, was found to be approximately $0.5 \mathrm{~g}$. and $14.0 \mathrm{~g}$. respectively in $100 \mathrm{~g}$. of water at $20^{\circ}$. Fittig ${ }^{2}$ using this method boiled the acids with barium carbonate but this is not convenient when using large quantities.

Sixty g. of the mixed acids was made into a paste with water and warmed with $12 \tilde{5} \mathrm{cc}$. of conc. ammonia on a water-bath for 20 minutes; more water was then added to dissolve the ammonium salts, and the solution was boiled to expel the excess of ammonia. When nearly neutral, the volume was made up to $350 \mathrm{cc}$. and a hot solution of $40 \mathrm{~g}$. of barium chloride in $70 \mathrm{cc}$. water added. After shaking for one hour and standing for 12 hours the barium terephthalate was filtered off, washed, and digested on a water-bath for 6 hours with $100 \mathrm{cc}$, of $15 \%$ hydrochloric acid; yield

1 Roser, Ber., 14, 940 (1.881).

'Fittig, Ann., 153, 269 (1870). 
of terephthalic acid $11 . \tilde{j} \mathrm{~g}$. The combined filtrates were acidified affording $47 \mathrm{~g}$. of isophthalic acid.

Further purification of the acids was effected by recrystallization of the dimethyl esters. Twenty $\mathrm{g}$. of isophthalic acid and $150 \mathrm{cc}$. of methyl alcohol saturated with hydrogen chloride on standing for 36 hours gave $19 \mathrm{~g}$. of dimethyl isophthalate, m. p. $66^{\circ}$ to $67^{\circ}$. Ten g. of terephthalic acid boiled for 7 hours with $150 \mathrm{cc}$. of methyl alcohol and $15 \mathrm{cc}$. of conc. sulfuric acid gave $8 \mathrm{~g}$. of dimethyl terephthalate, m. p. $141^{\circ}$.

o-Carbomethoxy-benzoyl Chloride with Benzene and Aluminum Chloride.-Six $\mathrm{g}$. of 0 -carbomethoxy-benzoyl chloride was dissolved in $80 \mathrm{cc}$. of benzene, cooled to $10^{\circ}$, and $10 \mathrm{~g}$. of aluminum chloride added gradually with shaking. After standing for one hour at room temperature the mixture was kept at $80^{\circ}$ for 7 hours and then poured into $100 \mathrm{cc}$. of $10 \%$ hydrochloric acid. After distilling off the benzene the ester was lydrolyzed with alcoholic potassium hydroxide, water was added and the solution was acidified with hydrochloric acid. The precipitate when recrystallized from ethyl alcohol gave $4.7 \mathrm{~g}$. of o-benzoylbenzoic acid.

$m$-Carbomethoxyl-benzoyl Chloride with Benzene and Aluminum Chloride.-Five $\mathrm{g}$. of $m$-carbomethoxy-benzoyl chloride was dissolved in $90 \mathrm{cc}$. of benzene and $9 \mathrm{~g}$. of aluminum chloride added. The mixture was kept at $45^{\circ}$ to $50^{\circ}$ for 5 hours and then at $80^{\circ}$ for 7 hours. After hydrolysis of the ester and recrystallization from dilute alcohol the yield of $m$-benzoyl-benzoic acid, m. p. $161-162^{\circ}$, was $3.9 \mathrm{~g}$.

Silver salt. Calc. for $\mathrm{C}_{14} \mathrm{H}_{8} \mathrm{O}_{3} \mathrm{Ag}$ : $\mathrm{Ag}, 32,4$. Found: 31.9 .

This acid had previously been prepared by Doebner ${ }^{3}$ from benzoic anhydride, benzoyl chloride and zinc chloride, by Ador ${ }^{4}$ as a by-product in the preparation of isophthalophenone, and by Senff ${ }^{5}$ who oxidized benzyl-toluol. None of these methods give nearly as good a yield as was obtained above.

p-Carbomethoxy-benzoyl Chloride with Benzene and Aluminum Chloride.-Five g. of $p$-carbomethoxy-benzoyl chloride, $50 \mathrm{cc}$. of benzene and $8.5 \mathrm{~g}$. of aluminum chloride were heated at $45^{\circ}$ to $50^{\circ}$ for 5 hours and then on a boiling water-bath for 5 hours. After hydrolysis of the ester the p-benzoyl-benzoic acid was separated from terephthalic acid by dissolving in alcohol and recrystallized by the addition of water, m. p. $194^{\circ}$; yield, $4 \mathrm{~g}$; terephthalic acid recovered, $2 \mathrm{~g}$.

One g. of the acid dissolved in thionyl chloride and added to methyl alcohol gave after recrystallization from methyl alcohol $1 \mathrm{~g}$. of methyl p-benzoyl-benzoate, m. p. 106-107 .

${ }^{3}$ Doebner, Ber., 14, 647 (1881).

"Ador, ibid., 13, 320 (1880).

'S Senff, Ann., 220, 236 (1883). 
$o$-Carbomethoxy-benzoyl Chloride with Toluene and Aluminum Chloride. - Five g. of 0 -carbomethoxy-benzoyl chloride, $50 \mathrm{cc}$. toluene, and $8.5 \mathrm{~g}$. of aluminum chloride were heated at $45^{\circ}$ to $50^{\circ}$ for 5 hours and then on a boiling water-bath for 7 hours. After addition of hydrochloric acid and removal of the toluene the reaction product was separated by the addition of ether, hydrolyzed with alcoholic potassium hydroxide and recrystallized from dil. alcohol, m. p. $96-100^{\circ}$; dried in a vacuum at $80^{\circ}, \mathrm{m}$. p. $138^{\circ}$ to $40^{\circ}$. The acid was fused with potassium hydroxide for 20 minutes at $200^{\circ}$ and gave a mixture of benzoic acid and $p$-toluic acid. As it was not easy to separate these acids the mixture was boiled for 3 hours with alkaline permanganate solution, acidified and the product esterified with methyl alcohol. The ester recrystallized from alcohol melted at $140^{\circ}$. This identifies it as dimethyl terephthalate and identifies the product of hydrolysis as p-toluic acid. The original acid is, therefore, $p$-toluyl-o-benzoic acid. This acid has been prepared from phthalic anhydride, toluene and aluminum chloride by Limpricht ${ }^{6}$ and others.

$m$-Carbomethoxy-benzoyl Chloride with Toluene and Aluminum Chloride.-Five $g$. of $m$-carbomethoxy-benzoyl chloride was dissolved in $60 \mathrm{cc}$. of benzene and, after cooling the solution to $10^{\circ}, 9 \mathrm{~g}$. of aluminum chloride was added gradually. After standing at room temperature for one hour, the mixture was heated on a water-bath for 10 hours. The product was hydrolyzed with alcoholic potassium hydroxide and the acid obtained was recrystallized from hot methyl alcohol. Yield, 4.0 g.; m. p. $172^{\circ}$.

Silver salt. Calc. for $\mathrm{C}_{15} \mathrm{H}_{11} \mathrm{O}_{3} \mathrm{Ag}: \mathrm{Ag}, 31$.1. Found: 30.8 .

On fusion with potassium hydroxide and oxidation of the acid product with potassium permanganate, terephthalic acid, identified by its methyl ester, was obtained. The method of preparation and the product of hydrolysis identify the product of this reaction as $p$-toluyl- $m$-benzoic acid, not previously described.

One g. of $p$-toluyl-m-benzoic acid was dissolved in thionyl chloride, the excess of thionyl chloride removed and $25 \mathrm{cc}$. of methyl alcohol added. After the reaction ceased the solution was poured into cold water and the ester recrystallized from methyl alcohol, m. p. $108^{\circ}$. Yield of methyl $p$-toluyl- $m$-benzoate, $0.9 \mathrm{~g}$.

$p$-Carbomethoxy-benzoyl Chloride with Toluene and Aluminum Chloride.-Five g. of $p$-carbomethoxy-benzoyl chloride, $60 \mathrm{cc}$. of toluene, and $9 \mathrm{~g}$. of aluminum chloride were heated for 9 hours at $40-50^{\circ}$ and then for 2 hours on a boiling water-bath. After washing the reaction product with dil. sodium hydrogen carbonate solution, it was hydrolyzed with alcoholic potassium hydroxide and the acid recrystallized from methyl alcohol; m. p. $228^{\circ}$; yield 4.4 g. The methyl ester was prepared; m. p.

' Limpricht, Ann., 299, 300 (1898). 
$126^{\circ}$. $p$-Toluyl-p-benzoic acid had previously been prepared by Limpricht ${ }^{7}$ by oxidizing $p, p$-ditolyl ketone.

$o$-Carbomethoxy-benzoyl Chloride with $m$-xylene and Aluminum Chloride.-Five g. of $o$-carbomethoxy-benzoyl chloride and $50 \mathrm{cc}$. of $m$-xylene were cooled to $10^{\circ}$ and $8.5 \mathrm{~g}$. of aluminum chloride was added gradually. After the initial reaction had ceased the mixture was warmed on a water-bath until hydrogen chloride ceased to come off. After acidification and removal of the $m$-xylene the reaction product was extracted with chloroform, hydrolyzed with alcoholic potassium hydroxide and recrystallized from benzene as fine needles; m. p. $139-140^{\circ}$; yield, $3.5 \mathrm{~g}$.

Silver salt. Calc. for $\mathrm{C}_{18} \mathrm{H}_{13} \mathrm{O}_{3} \mathrm{Ag}: \mathrm{Ag}, 29.9$. Found: 30.2 .

On fusion of the acid with potassium hydroxide for 30 minutes at $160^{\circ}$ to $170^{\circ}$, and sublimation of the acid product, benzoic acid and 2,4-dimethylbenzoic acid, m. p. $124^{\circ}$ to $126^{\circ}$, were identified. The acid is therefore 2,4-dimethyl-benzoyl-o-benzoic acid and is identical with the acid prepared by Meyer $^{8}$ from phthalic anhydride, $m$-xylene and aluminum chloride. Meyer gave no melting point.

$m$-Carbomethoxy-benzoyl Chloride with $m$-xylene and Aluminum Chloride.-Five g. of $m$-carbomethoxy-benzoyl chloride, $40 \mathrm{cc}$. of $\mathrm{m}$ xylene and $8.5 \mathrm{~g}$. of aluminum chloride were kept at $20^{\circ}$ for 5 hours and then on a boiling water-bath for 6 hours. After acidification and removal of the $m$-xylene the reaction product was extracted with chloroform, washed with dil. sodium hydrogen carbonate solution, hydrolyzed with alcoholic potassium hydroxide and acidified; yield of crude acid, $6.0 \mathrm{~g}$. Recrystallized from hot methyl alcohol the acid melted at $168^{\circ}$; yield, $4.0 \mathrm{~g}$.

Silver salt. Calc. for $\mathrm{C}_{16} \mathrm{H}_{13} \mathrm{O}_{3} \mathrm{Ag}: \mathrm{Ag}$, 29.9. Found: 30.0 .

On fusion of the acid with potassium hydroxide for 20 minutes at $170^{\circ}$ to $80^{\circ}$ and sublimation of the acid products the sublimate contained benzoic acid and 2,4-dimethyl-benzoic acid, m. p. $126^{\circ}$, and the residue from the sublimation was isophthalic acid, identified by the formation of its methyl ester. The greater part of the acid decomposes into isophthalic acid and $m$-xylene, but part of it gives benzoic acid and 2,4dimethyl-benzoic acid. The acid is, therefore, 2,4-dimethyl-benzoyl-mbenzoic acid.

One g. of 2,4-dimethyl-benzoyl-m-benzoic acid was warmed with thiony1 chloride until the reaction ceased and the resulting acid chloride was poured into methyl alcohol. The ester was precipitated by adding water and recrystallized from methyl alcohol, giving small needles; m. p. $73^{\circ}$.

$p$-Carbomethoxy-benzoyl Chloride with $m$-xylene and Aluminum Chloride.-Five g. of $p$-carbomethoxy-benzoyl chloride, $40 \mathrm{cc}$. of $\mathrm{m}$ -

7 Limupricht, Ann., 312, 92 (1900).

- Meyer, Ber., 15, 636 (1882). 
xylene and $8.5 \mathrm{~g}$. of aluminum chloride were kept at $45^{\circ}$ to $50^{\circ}$ for 5 hours and then at $80^{\circ}$ for 7 hours. The acid product was obtained as in the previous experiment and after recrystallization from methyl alcohol melted at: $184^{\circ}$ to $5^{\circ}$; yield, $4.5 \mathrm{~g}$.

Silver salt. Calc. $\mathrm{C}_{16} \mathrm{H}_{13} \mathrm{O}_{3} \mathrm{Ag}$ : $\mathrm{Ag}, 29.9$. Found: 30.0 .

Fusion with potassium hydroxide gave benzoic acid, 2,4-dimethylbenzoic acid, and terephthalic acid, identified by the formation of its dimethyl ester. In this case, again, part of the acid decomposed to benzoic acid and 2,4-dimethyl-benzoic acid and part to $m$-xylene and terephthalic acid. The acid is, therefore, 2,4-dimethyl-benzoyl-p-benzoic acid.

The methyl ester of 2,4-dimethyl-benzoyl-p-benzoic acid prepared from the acid chloride by adding methyl alcohol and recrystallizing from methyl alcohol was obtained as long, colorless needles; m. p. $59^{\circ}$.

\section{Summary.}

1. A method has been described of preparing isophthalic acid and terephthalic acid from commercial xylene.

2. The reaction of each of the carbomethoxy-benzoyl chlorides with aluminum chloride and benzene, toluene, and $m$-xylene, respectively, has been studied. In each case, the reaction with toluene takes place in the para position to the methyl group, and with $m$-xylene in the para position to one of the methyl groups.

3. New and improved methods of preparing $m$-benzoyl-benzoic acid, $p$-benzoyl-benzoic acid and some of their derivatives have been given.

4. The following new compounds have been prepared: $p$-toluyl-mbenzoic acid, m. p., $172^{\circ}$; methyl-p-toluyl-m-benzoate, m. p., $108^{\circ} ; 2,4$ dimethyl-benzoyl-m-benzoic acid, m. p. $168^{\circ}$; methyl-2,4-dimethyl-benzoyl- $m$-benzoate, m. p. $73^{\circ}$; 2,4-dimethyl-benzoyl-p-benzoic acid, m. p. $185^{\circ}$; methyl-2,4-dimethyl-benzoyl-p-benzoate, m. p. $59^{\circ}$.

This research was made under the direction of Professor F. B. Allan.

Toronto, Canada. 